\title{
The Analysis of Wuxi Real Estate Market Based on the House Price-to-Income Ratio
}

\author{
Yao Meng ${ }^{a}$, Xun Liu ${ }^{b}$ and Ziqi Wang ${ }^{c}$ \\ School of Environment and Civil Engineering, Jiangnan University, Wuxi 214122, China \\ a945718713@qq.com, bliuxun8127@163.com, c541982949@qq.com
}

Keywords: House price-to-income ratio; controlling variables; moving average method; real estate market.

Abstract. On the basis of house price-to-income ratio we analyze the present Wuxi real estate market from the aspect of the districts, income levels and the comparison with other cities by controlling variables. Besides we predict that the Wuxi house price-to-income ratio of 2015 will probably goes to 7.71 by using moving average method, which is in the reasonable interval. Hence we think the rise extent of the Wuxi house price is rational. However the purchasing power of different people is out of balance and there exists a gap among each district.

\section{Introduction}

Houses are necessaries in our usual life which are playing an increasingly important role in the national economy. In recent years with the rapid development of the real estate market, the house price rises in a high speed and the residents' income also goes up. Thus there exists some arguments about whether the rise extent of the house price has exceeded the purchasing power of residents and whether the house price is rational. The house price-to-income (PIR) ratio is a composite indicator in the world used to measure the capacity of house consumption and the house price level. Since PIR is easy to calculate it is now widely recognized by scholars.

Wuxi is located in the southern part of Jiangsu Province in China. There are seven districts and two counties in Wuxi. It covers an area of 4.63 thousand square kilometers and it has about 6.5 million permanent residents. In our paper we use the PIR index to analyze the current purchasing power of residents and the development situation of the real estate market by taking Wuxi for example.

\section{The Calculation and Reasonable Interval of PIR}

Calculation of PIR. PIR is used to describe the ratio of house price to the average annual income of each urban household in a wide range. There now exists many definitions about PIR. The World Bank defines PIR as the ratio of the average price of each commercial housing to the annual income of each urban household. Some Chinese scholars define it as the ratio of a specific kind of commercial house price to the disposal income of a correspondent family[1]. In sum the basic calculation formula of PIR is

$$
\mathrm{PIR}=\frac{\text { the house price }}{\text { the annual income of a family }}
$$

Before calculating the exact number of PIR we firstly need to specify the related indexes.

House price: The house price in the formula represents the market price determined by the effective demand and supply. In 1999 China's second-hand house market was fully launched which reduced the average market price. If we only use the price of the new houses the calculation result may be larger than the accurate value. Therefore in our paper we use the weighted price (WP) of the new houses and the second-hand houses.

The residential area: There are mainly two methods used to determine the residential area(RA). The one takes a unified number as the residential area such as 75 square meters or 80 square meters. The other uses the product of the family population and the per capita residential area. Considering 
the fact that the residential area is a vital factor for different income classes when purchasing a house and it also influence the house price greatly, we use the latter method to calculate PIR.

Income: We take the per capita disposal income(DI) in the calculating formula

In sum we obtain:

$$
P I R=\frac{W P \times R A \times \text { family population }}{D I \times \text { family population }}=\frac{W P \times R A}{D I}
$$

Reasonable Interval of PIR. When the PIR of an area is in the reasonable interval, we could think that the development of the real estate market corresponds with the residents' purchasing power. The World Bank once declared that the reasonable interval of PIR is 4-6. However the value of PIR varies greatly in different area and it will be also influenced by the economy. Some Chinese scholars also have used many other methods to estimate the reasonable interval of China, for example 3.38-6.75 ${ }^{[2]}$ and 2.2-5.8 ${ }^{[3]}$. We use $3.13-10.43^{[4]}$ as the reasonable interval which is based on the repayment of principal and interest waiting for the forehead.

\section{Analysis on the PIR of Wuxi}

Based on the analysis of the calculation formula and the reasonable interval above, we calculate the PIR of Wuxi from the aspect of districts, income levels and the comparison with other cities by controlling variables. Furtherly we could conclude the present development situation of Wuxi real estate market.

The PIR of different districts. According to the data declared by the bureau of house property right in Wuxi we can obtain the average price of the new house and the second-hand house in each district and the per capita residential area $\left(38 \mathrm{~m}^{2}\right)$. The statistic yearbook of Wuxi also shows that the per capita disposal income in 2014 is 41731 yuan. Hence we could calculate the PIR of each district in Wuxi, as listed in Table 1:

Table 1 The PIR of each district in Wuxi

\begin{tabular}{cccccccc}
\hline District & $\begin{array}{c}\text { Beitang } \\
\text { District }\end{array}$ & $\begin{array}{c}\text { Binhu } \\
\text { District }\end{array}$ & $\begin{array}{c}\text { Chongan } \\
\text { District }\end{array}$ & $\begin{array}{c}\text { Huishan } \\
\text { District }\end{array}$ & $\begin{array}{c}\text { Nanchang } \\
\text { District }\end{array}$ & $\begin{array}{c}\text { Xin } \\
\text { District }\end{array}$ & Wuxi \\
\hline New house & 7678 & 10406 & 8804 & 6214 & 10508 & 7244 & 8379 \\
Second-hand & 6309 & 8309 & 6989 & 6470 & 6875 & 7030 & 7289 \\
house & & & & & & & \\
WP & 7195.54 & 9666.98 & 8164.36 & 6304.22 & 9227.66 & 7168.58 & 7994.86 \\
PIR & 6.55 & 8.80 & 7.43 & 5.74 & 8.40 & 6.53 & 7.28 \\
\hline
\end{tabular}

As indicated in Table 1, the PIR of each district in Wuxi is in the reasonable interval 3.13-10.43. Therefore we can conclude that the house price is within the reach of an average income resident in Wuxi. To demonstrate the relations of each district better we import the house price of 122 communities into Surfer software, as is shown in Fig. 1.

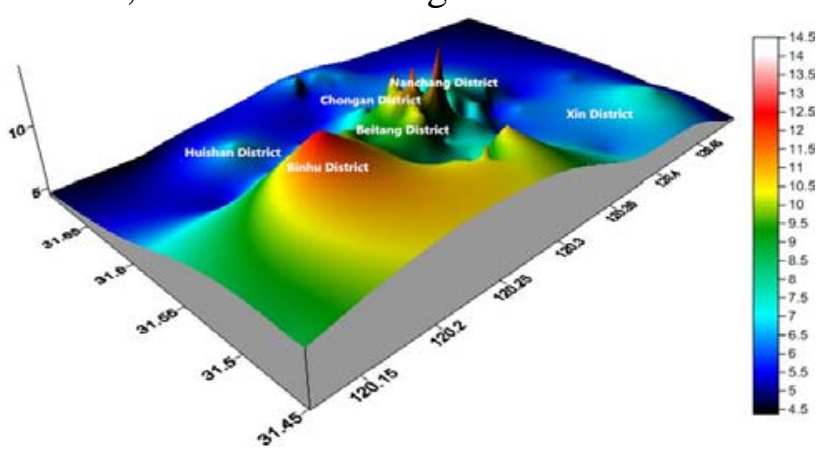

Fig. 1 The PIR of each district in Wuxi

Fig. 1 shows that many peak values of PIR has appeared in Nanchang District, Binhu District and Chongan District. These values have almost reach around 13 which has far exceeded the higher limit of the reasonable interval 10.43. Most of these value are from the high-end communities. In the 122 communities we have researched, the high-end communities almost takes up about 20 percent. By 
using interval estimation, we infer that the high-end communities account for almost $13 \%-27 \%$ of the new communities in Wuxi. In reality the residents have not form enough demand for these high-end communities thus making the supply ratio of these communities much larger than the normal. This also accounts for the fact that the real estate inventory has kept large in recent years.

The PIR of different income levels. In 2014 the annual house price of Wuxi is 7995 yuan per square kilometers. According to our survey result, we classify the residents into seven income levels. Then we calculate the PIR of each income level by keeping the house price still(7995yuan $\left./ \mathrm{m}^{2}\right)$. The data is shown in Table 2.

Table 2 The PIR of each income level in Wuxi of 2014

\begin{tabular}{cccc}
\hline Income Level & Proportion & Income Interval & PIR \\
\hline The lowest income households & $10 \%$ & Less than 14796 & 32.09 \\
Low income households & $10 \%$ & $14796-25452$ & 15.10 \\
Lower middle income households & $20 \%$ & $25452-33252$ & 10.35 \\
Middle income households & $20 \%$ & $33252-41172$ & 8.16 \\
Higher middle income households & $20 \%$ & $41172-51180$ & 6.58 \\
High income households & $10 \%$ & $51180-66744$ & 5.15 \\
Highest income households & $10 \%$ & More than 66744 & 4.08 \\
\hline
\end{tabular}

Table 2 shows that the PIR from the highest income households to the lower middle income households is in the reasonable interval. On the contrary the low income households and the lowest income households' PIR have far exceeded the higher limit of the reasonable interval. That is to say about 20 percent of the residents in Wuxi can't afford buying a house under the present average price.

The comparison analysis with some cities in China. Based on the cities' economy development and locations, we selected 12 representative cities to compare with Wuxi from the aspect of PIR. According to the statistics published by the bureau of statistics website, we can obtain the PIR of the 12 cities. The data is summarized in Table 3.

Table 3 The PIR of 12 cities in China of 2014

\begin{tabular}{ccccc}
\hline City & WP & RA & DI & PIR \\
\hline Beijing & 32042 & 31 & 43910 & 22.62 \\
Shanghai & 32029 & 33.9 & 47710 & 22.76 \\
Tianjin & 10578 & 30 & 31506 & 10.07 \\
Chongqing & 7157 & 33.59 & 25133 & 9.57 \\
Chengdu & 8036 & 32.9 & 32810 & 8.06 \\
Nanjing & 13814 & 32.21 & 42568 & 10.45 \\
Hangzhou & 16133 & 34.3 & 44632 & 12.40 \\
Shenyang & 7296 & 31.2 & 34233 & 6.65 \\
Taiyuan & 6916 & 29 & 25768 & 7.78 \\
Xian & 6746 & 28.7 & 33100 & 5.85 \\
Xining & 5927 & 25.8 & 21291 & 7.18 \\
Hohhot & 6889 & 31.5 & 34723 & 6.25 \\
Wuxi & 7995 & 38 & 41728 & 7.28 \\
\hline
\end{tabular}

According to the data above, we can see that the PIR is related to the development of economy. For those cities like Beijing and Shanghai whose economy is highly developed, the PIR is far beyond the higher limit of the reasonable interval; for those secondary cities like Chengdu and Nanjing, the PIR are almost in the reasonable interval. However the PIR of the cities in the western and middle part of China whose economy is less developed are always lower than that of the eastern part. The PIR of Wuxi are basically in the mid-level of the secondary cities.

\section{Moving average method}

In order to predict the future development of the real estate market in Wuxi, we calculate out the PIR of recent 10 years based on the statistics published on the Wuxi bureau of statistics website. The results are shown in Table 4. 
Table 4: The PIR of Wuxi in recent 10 years

\begin{tabular}{ccccccccccc}
\hline Year & 2005 & 2006 & 2007 & 2008 & 2009 & 2010 & 2011 & 2012 & 2013 & 2014 \\
\hline WP & 3971 & 4163 & 4592 & 5208 & 5575 & 7174 & 8268 & 7882 & 8028 & 7995 \\
RA & 27.1 & 31.3 & 30.7 & 33.4 & 39.4 & 39.2 & 38.32 & 36.4 & 37.96 & 38 \\
DI & 16005 & 18189 & 20898 & 23605 & 25027 & 27750 & 31638 & 35663 & 38999 & 41728 \\
PIR & 6.72 & 7.16 & 6.75 & 7.37 & 8.78 & 10.13 & 10.01 & 8.04 & 7.81 & 7.28 \\
\hline
\end{tabular}

As is indicated in Table 4 we can know that the general trend of Wuxi house price is going up in recent 10 years. From year 2005 to 2011, the house price is rising all the time. Besides the growth rate is larger than other years from 2009 to 2011. In 2011 the local government has carried out some control policies which has effectively reduced the house price. Until now the price is rising steadily. Correspondently the PIR is going up with the price from 2005 to 2011. The highest value once reached 10.13. Since 2012 although the price is rising, the general trend of PIR is going down. That is to say the real estate market in Wuxi have entered a relatively healthy develop period.

By using the moving average method we predict the PIR of Wuxi in 2015. Let the moving interval $\mathrm{k}=3$ and $\mathrm{k}=5$. The prediction result are shown in Fig. 2.

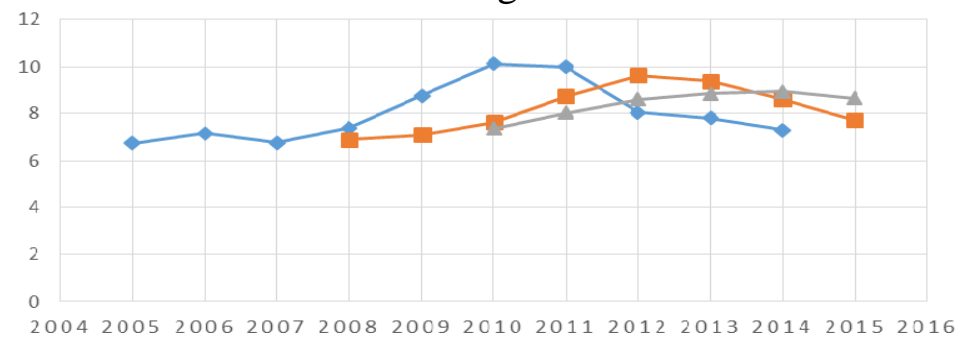

Fig. 2 The moving average method prediction result

When $\mathrm{k}=3$, the prediction error $R=2.54$. When $\mathrm{k}=5, R=3.01$ and therefore we use $\mathrm{k}=3$. The final prediction result about the PIR of Wuxi in 2015 is 7.71.

\section{Conclusion}

The general PIR of Wuxi is falling down and is in the reasonable interval. Thus on the whole the growth rate of the house price is rational. However there exist obvious gaps among different income level households and the purchasing power of residents is out of balance. Besides the estate market is also unbalanced in different districts. Most of the high-end communities gathered in some districts and the PIR has exceed the reasonable interval.

In order to regulate the real estate market, on the one hand the house structure need to be adjusted. The government along with the market should regulate the proportion of various newly-built houses and invest more to build social homes. On the other hand the second-hand house market need to be activated. The legislature should improve related laws. Hence the government could supply gradient consumption of houses for residents of all income levels.

\section{References}

[1] Jiuyun Shen. The investigation on the meaning of house price-to-income.Journal of Central University of Finance and Economics,2006(6):75-79

[2] Yanjie Che. The house purchasing power of residents in Jilin Province.Contemporary Economic Research,2001(5):57-60

[3] Rujin Ji \&Lingling Chen. The family accept ability on the house to price ratio.Gold Master,1998(5):39-41

[4] Cong Geng. A study of commercial property price to income ratios under different objectives-Taking Nanchang city as an example.Nanchang: Graduate School of Jiangxi Normal University, 2011 